\title{
Weight Stigma in Healthcare Settings in the United Kingdom: A Review
}

\author{
Osinachi Akanwa Ekeagwu ${ }^{1}$ \\ ${ }^{1}$ Department of Allied and Public Health, Faculty of Medical Sciences, Anglia Ruskin University, Cambridge, \\ United Kingdom \\ Correspondence: Osinachi Akanwa Ekeagwu, Department of Allied and Public Health, Faculty of Medical \\ Sciences, Anglia Ruskin University, Cambridge, United Kingdom. E-mail: osinachi.ekeagwu@pgr.anglia.ac.uk
}

Received: August 4, 2017 Accepted: September 5, 2017 Online Published: September 13, 2017

doi:10.5539/gjhs.v9n10p155 URL: https://doi.org/10.5539/gjhs.v9n10p155

\begin{abstract}
Due to weight stigma, obese and overweight individuals are stereotyped, rejected and victimised by the public. The pervasion of this discrimination in healthcare settings is concerning given that the healthcare setting plays a crucial role in influencing health and shaping perception of health conditions. Without adequate support and little public attention, obese individuals are primarily left on their own to deal with ongoing prejudice unless addressed through vigorous research and strategic interventions at individual, interpersonal, organisational and community levels, and through policy implementation.
\end{abstract}

Keywords: healthcare, obesity, stigma, weight-stigma

\section{Introduction}

Stigma is a discrediting attribute which results in an individual being reduced from a whole and usual person to a tainted and shameful one (Goffman, 1963). The individual is consequently marked as different and devalued. Weight differences have been identified to result in stigma, particularly affecting overweight and obese individuals. Obesity being a complex problem resulting from a range of biological, physiological and social factors apparently poorly understood, affected individuals often become withdrawn from society through experiences of stigma expressed in form of bias, stereotyping and rejection (Hitchcock \& Pugh, 2002). Such discrimination can often lead to social and psychological problems which can further complicate their health.

Obesity and overweight currently amount to an estimated direct cost of $£ 6$ billion per year in the United Kingdom (HSCIC, 2014), a proportion of which accrues from the purchase of expanding therapies (pharmacological, non-pharmacological and surgical). The availability of various therapies requires patients and healthcare practitioners to make informed choices regarding the best-suited therapies. While these choices are in part determined by clinical guidelines, they are also influenced by the cost of treatment, availability, knowledge, and motivation of the health practitioner to introduce them (NICE, 2006; 2010). After the introduction of therapy, the health practitioner may also be responsible for providing psychological support to obese and overweight individuals in adopting self-care and lifestyle changes. This emphasises that the relationship between obese or overweight individuals and the healthcare staff is crucial in the management of obesity. Hence, any factor which compromises this relationship may threaten the management of the obese patient. A social factor such as stigma can hamper this relationship thereby limiting access of obese and overweight individuals to quality health care. This review, therefore focuses on weight stigma in healthcare settings in the United Kingdom, identifying possible forms, causes, and associated factors, as well as recommends approaches towards minimising it.

\section{Attitudes of Healthcare Staff Promoting Weight-Bias}

Negative stereotypes arising from weight stigma are widespread in healthcare and translate into inequities, leaving overweight and obese individuals vulnerable to unfair treatment. Harvey and Hill (2001) in a study of 255 British healthcare professionals, found that overweight people were perceived to have low self-esteem, poor health, and less sexual attractiveness. Providers also believed that sedentariness and overeating were the most important causes of overweight. Epstein and Ogden (2005) observed similarly in their qualitative study of 21 primary care physicians, in which physicians reported beliefs that obesity was caused by lack of exercise and unhealthy diet and that the patients were responsible for managing their weight. They expressed frustration that patients were in the 
habit of making excuses to why they found it challenging complying with lifestyle recommendations. The corresponding victim-blaming approach toward obesity was found in another survey of 89 general practitioners (Ogden et al., 2001) deeming the obese responsible for both the cause and solution to their weight problem. Despite the seemingly unanimous views that obese patients lack the motivation to make lifestyle changes and are noncompliant with treatment recommendations, it appears physicians' perceptions of obese patient motivation is biased. For instance, Ogden, et al. (2001) noted that notwithstanding physicians' perception, the patients in the study were more likely to attribute obesity to other causes such as medical issues and low income. Expatiating on the differing perceptions between physicians and obese patients, Befort, et al. (2006) highlighted that patients' self-reported level of motivation regarding weight management was significantly higher than physicians' perceptions. Based on their findings, on a motivation scale of 10 ( 10 being completely motivated $=100 \%)$, female patients reported $30 \%$, while male patients reported $21 \%$, whereas physicians rated only $2.5 \%$ and $3.1 \%$ of their female and male patients respectively. Evidently, further research investigating the factors responsible for the differing perceptions between the physicians and the patients is required as it may influence endorsement of weight stigma when considering explicit and implicit measures of stigma.

Contrastingly, Loomis, et al. (2001) in a survey of the attitudes of 214 military family physicians found that despite the perceived low levels of motivation by some $(25 \%)$, the majority reported positive attitudes toward obese patients.

Studies have also demonstrated nurses to show negative attitudes toward obese patients. A 2006 review on nurses' attitudes reported that nurses consistently expressed bias towards obese patients reflecting common weight-based stereotypes of laziness, non-compliance and lack of self-control (Brown, 2006). In another study of 398 nurses, almost $69 \%$ agreed that personal choices about food and physical activity explain why an individual becomes obese, a third agreed obesity is due to a lack of willpower concerning food, and only $8.2 \%$ agreed that obese people are motivated about lifestyle change (Brown et al., 2006). It was also observed that nurses with lower BMIs expressed more negative perceptions of obesity compared to those with higher BMIs. More effort to explain the attitude of nurses towards obese patients was made by Brown and Thompson (2007) through qualitative interviews of 15 primary care nurses in England. Their observations revealed that although nurses were aware that obesity was a stigmatised condition and were careful to avoid weight-based stereotypes, some expressed issues with patients' noncompliance and wanting the "easy way out."

On the contrary, Zezulo and Seminara (2006) found that registered nurses had positive attitudes toward adult obese patients and were more concerned with providing respectful patient care. The study's low response rate (16.2\%) however suggests perhaps that only nurses who were sensitive to the needs of the obese patients chose to participate in the survey. In consideration of the lack of consensus regarding the stigmatising attitudes of nurses, Hankey, et al. (2003) studied the relationship between BMI and the attitude of nurses towards obese patients. In a systematic stratified sample of 1400 nurses, those with a healthy BMI had better knowledge and attitude to managing obese patients compared to those who were overweight. This evidence appears to stress the need to promote the uptake of healthy lifestyles among practitioners to enable them adequately support overweight patients. Leslie, et al. (2005) recognises this as a way of strengthening the "patient-physician relationship," iterating its crucial role in encouraging patient adherence to treatment.

Dietitians and fitness professionals are increasingly recognised in healthcare as agents supporting individuals through healthy weight management (Puhl \& Heuer, 2009). This group of practitioners have also been demonstrated to show weight bias attributes. A study (Harvey et al., 2002) of 187 British dietitians found that dietitians rated obese people less positively than overweight people and indicated that obese individuals were more responsible for their excess weight than the overweight.

Some studies have iterated the weight- bias attitudes of trainees for a range of health-related occupations, such as doctors, nurses, dietitians, psychologists, and nutritionists. Accordingly, they demonstrate stereotypical attitudes towards obese patients connoting poor self-control and lack of willpower, being sloppy, less likely to adhere to treatment, unsuccessful and responsible for their symptoms (Persky \& Eccleston, 2011; Swift et al., 2013a; Wigton $\&$ McGaghie, 2001). Use of derogatory remarks on obese persons by medical students has also been reported (Wear et al., 2006). Swift, et al. (2013a) in their study noted that the negative stereotypical attitudes among trainee nurses co-occurred with strong beliefs regarding the controllability of obesity. Such "controllability beliefs" as recorded in this study are particularly important, as Allison, Basile and Yuker (1991) suggest a positive correlation between beliefs that obesity is controllable and stigmatising attitudes towards obese people.

Beyond the attitudes of healthcare staff, the language used in consultation with obese and overweight individuals may have some implications particularly important in healthcare settings. A study (Tailor \& Ogden, 2009) 
highlights that the use of inappropriate language may have detrimental impacts on the patient- practitioner relationship, stating that certain language used by healthcare professionals may promote stigma and negatively impact patients' motivation by giving the impression that they are to blame for their weight. Terms such as "fat", "morbidly obese" and "chubby" are reported to be the most stigmatising and least motivating, whilst other terms more recommended are "weight", "unhealthy weight" and "overweight." Although the perception of what is acceptable language could vary based on cultural considerations, there is a need for effective communication in conveying necessary health information to obese patients.

\section{Patients' Perception of Weight Stigma in the Healthcare Setting}

Based on the findings of qualitative research involving 161 obese adults attending dietetic outpatient clinics (Thompson \& Thomas, 2000), the majority of respondents (84\%) agreed that most medical problems for which they visited clinic were blamed on their weight. Also, those with higher BMI were more likely to agree with the statements; "I am regarded as a second-class citizen" and "chairs are never big enough." The female subjects were also more likely to agree with the statement "nobody looks into why I am overweight - they just put me on diets." In another study, Brown (2006) conducted semi-structured interviews with 28 obese patients regarding their experiences in primary care. Participants reported they were reluctant to address weight concerns with healthcare providers and perceived that they would not be taken seriously. Participants also discussed concerns about the stigmatised nature of obesity and expressed that they expected negative stereotypes in primary care, however, mentioned nurse-led support groups could serve as an avenue for improving health-care services. Further assessing patients' perception of stigma, Wee, et al. (2002) studied 2,340 patients who completed self-report surveys and showed that compared to normal-weight patients, obese patients reported low levels of satisfaction with most aspects of medical care at their latest visit.

\section{Patients' Attitude Promoting Stigma}

More studies appear to have focussed on obese patients as victims of stigma while giving little attention to health care practitioners experiencing weight related stigma. Exploring primary care nurses' attitudes, beliefs and perceptions of their own body size, Brown and Thompson (2007) show that those with high BMI were victims of weight bias by patients. This "reverse" direction of stigma is necessary to consider as it could have significant impacts on the quality of care delivery.

\section{Healthcare Organisational Weight Management Practices Promoting Stigma}

Although the health care practitioners practise within the healthcare system and may be considered an entity with the health care provider in which they work, it may be necessary to consider them separately to avoid unfairly supposing that the stigmatising attitude noted among healthcare practitioners is intentional rather than related to other inadequacies of the health care provider or organisation itself. A correlational study by Brown (2006) investigating the beliefs and attitudes of primary care nurses with respect to obesity management indicates that only a minority $(21.6 \%)$ of nurses $(N=398)$ were confident at helping obese patients in weight management. Mercer and Tessier (2001) similarly observed that although general practitioners (GPs) and nurses understood obesity as a health problem, most of them were not confident managing obese patients. Through qualitative semi-structured interviews, others (Keyworth et al., 2013) have also found that nurses despite being willing are ill-equipped to manage obesity. Apparently, the use of inadequately skilled healthcare staff in the management of obesity translates into increased risk of mismanagement and stigma related practices. Hence the need for adequate training of healthcare staff and equipping healthcare facilities for effective management of obese and overweight patients.

\section{Impact of Weight Bias on Obese Patients}

\subsection{Low Utilisation of Healthcare Facilities}

After controlling for sociodemographic variables, health care access, and illness burden, Wee, et al (2000) found that severely obese white women were significantly less likely to undergo cervical cancer screening compared to normal-weight women. The women reported embarrassment or discomfort as the primary reason for not undergoing screening. These findings are concerning given the incidence of cancer and mortality rates in obese individuals (Reeves et al., 2007). Eliminating stigma-related barriers to receiving cancer screenings may be a useful approach towards weakening the relationship between excess body weight and cancer mortality. 


\subsection{Psychological Effects}

Although there is limited evidence in the United Kingdom, stigma may play an important role in fostering body image dissatisfaction among obese persons. Investigating the variation in body dissatisfaction in relation to age of onset of obesity among 105 obese subjects from clinical settings, Wardle, Waller and Fox (2002) showed that stigma increased the likelihood of body dissatisfaction especially when it occurred at an early onset. Their research though provides evidence regarding the psychological effects of stigma, it is worthwhile exploring the gender-related differences in the psychological effects of stigma.

It is noteworthy that weight stigma is associated with several physical and psychological disorders such as reduced physical activity, depression, low self-esteem and negative psychological coping mechanisms (Puhl \& Heuer, 2009). Nevertheless, most of these disorders have not been highlighted as related to weight stigma in the United Kingdom. This does not necessarily imply that weight-bias related disorders are non-existent or have a low prevalence in the United Kingdom, rather emphasises the gap in knowledge, an indication that little concern is given to weight bias. Perhaps these are related to the provision of sparsely scattered weight management and obesity care as short term projects across the country, and the separation of obesity management responsibility into tiers. According to the National Health Service England and Public Health England Working Group (NHS, 2014), this has created multiple responsibilities and challenged the ability of the healthcare to function as a coordinated service thereby leaving unresolved other challenges of obesity management such as derogation of responsibility, blame, and feelings of therapeutic helplessness.

\section{Discussion}

\subsection{Validity of Evidence on Weight Bias in the Healthcare Setting}

While considering the pervasiveness, impact, and factors associated with weight bias, it is necessary to critically assess the validity of the supporting evidence. Most of the reviewed evidence applied explicit measures (measures which are deliberately formed) in ascertaining stigma. This method, though acceptable in the conduct of research may be associated with biases related to demand characteristics and response bias (Rudman, 2004). Demand characteristics arise when the participants of a research form an interpretation of the research aims and subsequently modify their behaviour either due to the social acceptability of the elicited behaviour or with an intention to create an impression. And response bias is due to inaccurate responses resulting from misunderstanding a question, or issues with the wording of a question. Both sources of bias tend to reduce the validity of results, questioning the pervasiveness of stigma in the healthcare settings. To avoid these sources of bias, it may be necessary to employ implicit measures of attitude; those which are formed involuntarily and occur without conscious awareness, such as the Implicit Association Test (Greenwald, McGhee, \& Schwartz, 1998). This emphasises the need for careful consideration when applying the results, particularly of individual studies.

\subsection{Understanding Factors Promoting Stigma in Healthcare Settings}

Various factors contribute to the pervasion of stigma in the healthcare setting, including knowledge of the controllability of weight, negative perceptions and expectations of obese patients, and perceptions of responsibility. Beliefs about causes of obesity are important because they can influence healthcare practitioners' opinion about their responsibility and attitude towards obese clients. Research (Epstein \& Ogden, 2005; Brown, 2006; Brown et al., 2006) on perceptions of causes of obesity and individual responsibility indicate healthcare practitioners tend to lean towards obesity being an issue of lifestyle choice and personal responsibility, while the patients, on the other hand, seem more comfortable viewing the problem as caused by factors beyond their control. The disparate perceptions regarding controllability of obesity are likely associated with stigmatising attitudes from the healthcare practitioners and perceived stigma by obese patients. Another potential factor promoting the perception of weight bias is in the perceived comfort when discussing obesity. Brown (2006) showed that patients perceived that healthcare professionals were awkward about discussing obesity, which caused the patients to feel unsupported and left alone to carry their burden, interpreted as bias.

Of other health conditions likely to elicit stigma, Latner, et al. (2008) states that being obese or overweight is about the most likely. Perhaps it is due to the visibility of overweight and obesity, or already existing stigma in domains beyond the health setting. Contrastingly, Brown, et al (2006) revealed that the perception of stigma among obese patients was higher due to nursing of a general expectation of negative stereotypes in social interactions. Merrill and Grassley (2008) clarify that this expectation is fuelled from internal thought processes which make them more apt to confirm their experience of stigma, such that any least comment or attitude portrayed by healthcare practitioners becomes perceived as stigmatising. 
Also, worth considering is the issue of "responsibility." Regardless of obese or overweight patients' thoughts of who is to blame for their condition, when present in the healthcare setting, they seem to have some level of confidence and expectation of the healthcare practitioner. This may be perceived in some sense as transferring or sharing some burden with the health care practitioner who is in turn expected to proffer a solution. At this point, any attitude which is not in keeping with the obese patient's expectations may be interpreted as a stigma. And the practitioner, on the other hand, may easily feel the patient is attempting to shift responsibility, leading to the perception of irresponsibility or lack of motivation of the patient to help themselves. Rather than imply that perception of stigma is exaggerated, it shows obese and overweight patients are vulnerable.

Furthermore, in certain cases, the healthcare staff may not be able to help an overweight or obese client much due to challenges beyond their control. For example, studies (Camden, 2009; Bleich, Pickett-Blakely, \& Cooper, 2011) highlight that when caring for an obese patient, body-size can complicate even the most basic interventions regardless of the practice setting, and that obese patients often times may not fit and consequently may be unable to undertake procedures. In such case, despite that the challenge is not directly related to the practitioner, the obese patients may misperceive the attitude of healthcare staff as stigmatising.

\subsection{Is there a Justification for Weight Stigma?}

Albeit the likelihood of obese patients nursing a general expectation of negative stereotypes in social interactions (Hankey et al., 2003; Flint, Hudson, \& Lavallee, 2013), since the healthcare setting plays a significant role in caring and forming perceptions about health conditions, there is need to support patients through their challenging weight-management experiences rather than dismiss them on the grounds of their weight. Agreeably, physical size can constitute challenges in certain situations (Camden, 2009; Bleich, Pickett-Blakely, \& Cooper, 2011), however the way the patients are informed of this challenge seems important considering that the use of certain terminologies in addressing obese patients is more likely to be perceived as stigmatising than others (Swift et al., 2013a; Wee et al., 2002). More so, despite knowing that some factors precipitating obesity are controllable (Epstein \& Ogden, 2005), health practitioners need to understand that most patients may have already recorded unsuccessful attempts towards maintaining a healthy weight. Therefore, rather than regard them as unmotivated, they should be considered as individuals in need of better strategies for weight-management.

\subsection{How Can Weight-Bias Be Reduced?}

Interventions towards reducing weight-bias abound (Flint, Hudson, \& Lavallee, 2013), although most have been unsuccessful especially those attempting to address the beliefs about the controllability of obesity (O'Brien et al., 2010; Swift et al., 2013b). Poustchi, et al. (2013) for instance studied an intervention in which medical students were exposed to a 17-minute video titled "Weight Bias in Health Care", in addition to having discussions about their experiences with obese individuals. This intervention was said to be effective in increasing the belief that uncontrollable factors such as genetics were causes of obesity. Nevertheless, the authors failed to state if there was any impact on the students stigmatising attitudes. More recently, Kuschener, et al. (2014) in a study of an educational intervention on interactions with overweight and obese subjects reported it was effective in reducing stereotyping and increasing empathy and confidence in counseling skills in a sample of healthcare staff in training. However, follow-up analysis carried out 1-year later revealed that the reduction in stereotyping had reverted to the baseline level.

Besides educational interventions, other anti-fat strategies such as evoking empathy towards obese individuals, and the "social consensus" approach have been applied in experimental studies. In a study, Teachman, et al. (2003) had 153 subjects read first-person narratives of obese individuals who had experienced weight stigma. This did not improve attitudes compared with control conditions, but reduced implicit bias among overweight participants. Another study tested a media-based empathy intervention involving 108 participants who were made to view either an empathy-evoking video of obese persons or a non-weight related control video, followed by additional videos of obese persons who were presented positively (e.g., as competent) or negatively (e.g., as clumsy) (Gapinski et al., 2006). The empathy-evoking videos were not effective in improving implicit and explicit weight-bias attitudes.

Using the "social consensus" approach (Stangor, Sechrist, \& Josh, 2001) proposing that stereotypes and stigma are subject to one's perception of others' stereotypical beliefs, Puhl, Schwartz and Brownell (2005) in three experimental studies demonstrate that learning about the positive attitudes of others can be effective in reducing stigma toward obese people. Their findings, however, reflect only short term impact of the approach. Additionally, the authors' focus on the interpersonal level alone and failure to address internalised stigma raise doubt regarding the long-term effectiveness. 
Durso and Latner (2008) clarify that weight bias can be assessed from two perspectives; negative attributions made about "self" (internalised weight bias), and "others" (explicit weight bias). In this view, a model which focusses on both perspectives across multiple levels is necessary. A social ecological model has been recommended (Figure 1) targeting the individual or victim of stigma, and explicit aspects at the interpersonal, organisational, community and policy levels. Although this review emphases weight stigma in the healthcare setting, the consideration of weight stigma in other domains appears necessary for effective reduction of stigma, particularly as obese and overweight individuals also interact with other domains.

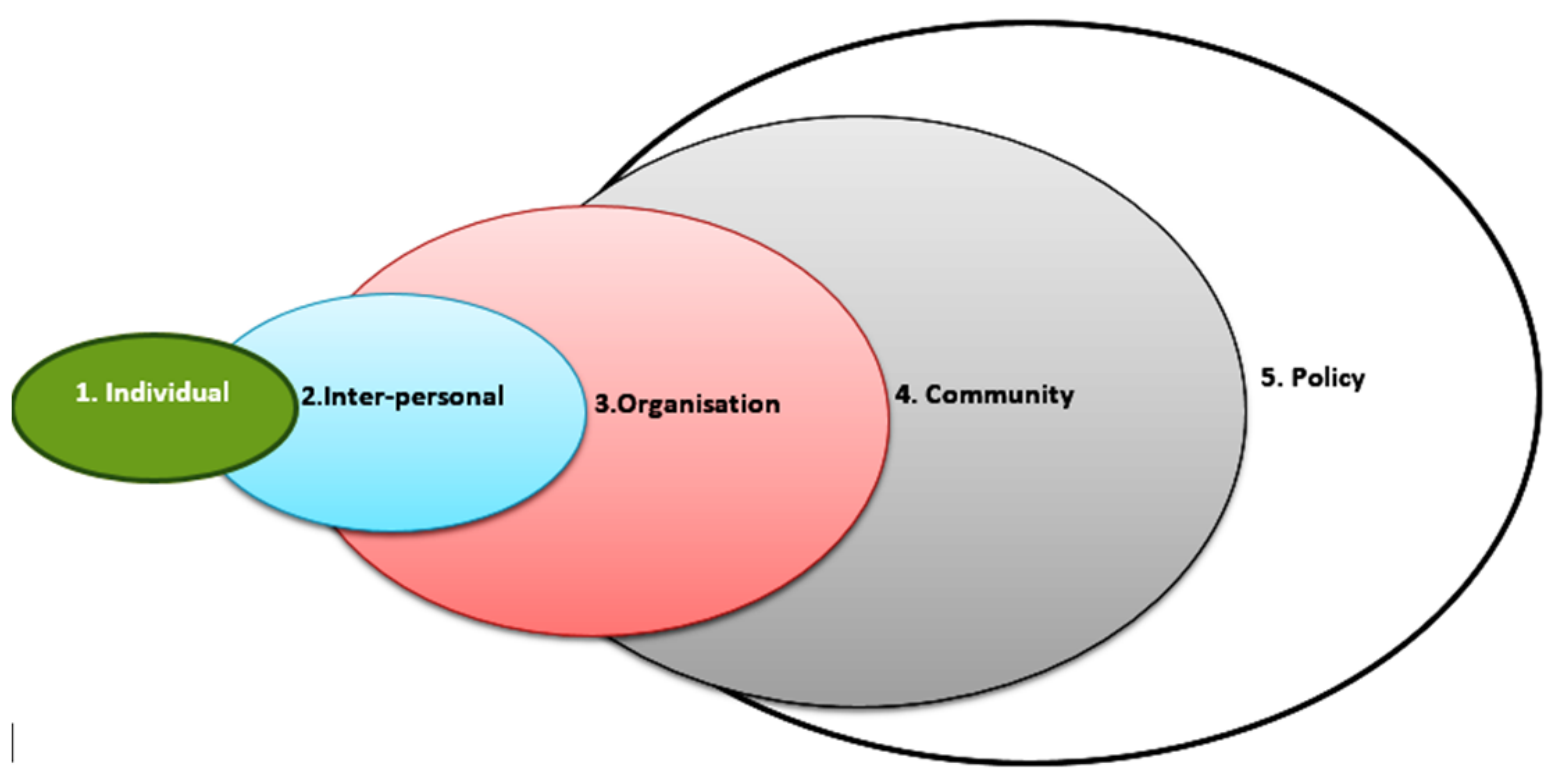

Figure 1. Social ecological model for reducing weight stigma

1). Individual: This level is concerned with the individual who is stigmatised because of their weight. Such individual should be informed about the risk of internalised stigma and coached on healthy lifestyle habits towards enhancing self-image. They should also be provided with information on how to positively manage perceived stigma in their environment. Individual-focused interventions though may not directly influence structural forces promoting stigma (Babalola, Fatusi, \& Anyanti, 2009), small changes initiated at this level if well timed and applied can result in lasting benefits (Johnson et al., 2010; Yeager et al., 2011). Valuable approaches at this level include cognitive-behavioural therapy integrating educational, behavioural and psychological techniques, values affirmation (Heijnders \& Van Der Meij, 2006) and belonging (Walton \& Cohen, 2011).

2). Interpersonal: Identifying close social circle-peers and family influences, and applying family-focused programs, peer programs and mentoring to reduce stigma, and foster healthy relationships. Important strategies would include community-based reintegration (Dalal, 2006) and creating inter-group contact to promote interactive exchanges between group members to provide support (Corrigan et al., 2012).

3). Organisation: At this level, the focus should be given to the different domains in which weight stigma has already been identified to occur such as in healthcare, schools, workplaces, media, and identifying the characteristics of these settings which promote weight bias. Strict organisational regulations should be set prohibiting weight stigma related attitudes. For such regulations to be effective, the appropriate definition of what constitutes weight stigma is necessary, and the consequences of promoting it should be clearly stated. In the schools and employment settings, compulsory training on the negative consequences of weight-bias should be conducted for students and employees respectively. Periodic stigma checks may also be conducted using implicit measures to evaluate impact sustainability and highlight need for retraining. Awards and other incentives should be provided to educational and healthcare and other institutions which promote body inclusivity.

4). Community: There is a need to promote cultural and social norms minimising weight stigma, by involving community-level institutions and advocacy groups which serve as potential ports of communication and support to reduce weight-bias. Public enlightenment campaigns should be conducted through such community groups. Interventions at this level are necessary to alter public perception about obese and overweight individuals. 
5). Policy: The essence of intervening at this level is to legally protect victims of weight bias. National policies should be regimented against the institutionalisation of weight stigma through the scrutiny of social, economic, health and educational programmes. This becomes necessary as some interventions aimed at promoting health may promote weight bias by using body weight as a standard for health and beauty (Latner \& Stunkard, 2003). Policies should also create standards in terms of facility and staff training for the management of overweight and obese patients in healthcare settings. Considering that weight stigma is a manifestation of social inequity (Alberga et al., 2016), policies should mandate institutions to make necessary provisions to accommodate the special needs of obese and overweight individuals.

Despite that various interventions have been stated with respect to specific levels, there remains a possibility of extended effects. For instance, interventions at the policy level may prompt community-level strategies towards reducing weight stigma. A similar effect was observed with interventions towards reducing HIV stigma in Senegal (Diop, 2000).

\section{Conclusion}

The presence of weight stigma with related health and physical consequences present challenges for individuals struggling with excess weight. Unfortunately, their experience in the healthcare setting- a place with a primary role in influencing health and forming perceptions of health conditions has not been different. This may in part be due to lack of legislation expressly prohibiting weight discrimination. Notwithstanding, given the European Court ruling that obesity can in severe cases constitute a disability (The guardian, 2014), weight-stigma would perhaps gain recognition by legislation in the nearest future. The role of policy in legally protecting victims of weight-bias cannot be overemphasised, although may be inadequate when applied as a single approach. For effective reduction of weight stigma, multiple culturally sensitive approaches are required across different levels of the concerned population.

\section{Competing Interests Statement}

The author declares that there are no competing or potential conflicts of interest.

\section{References}

Alberga, A. S., Russell-Mayhew, S., Kristin, M., von Ranson, \& Lindsay, M. (2016). Weight bias: a call to action. Journal of Eating Disorders, 4, 34. https://doi.org/10.1186/s40337-016-0112-4

Allison, D. B., Basile, V. C., \& Yuker, H. E. (1991). The measurement of attitudes toward and beliefs about obese persons. International Journal of Eating Disorders, 10, 599-607. http://doi.org/10.1002/1098-108X(199109)10:5<599::AID-EAT2260100512>3.0.CO;2-\#

Babalola, S., Fatusi, A., \& Anyanti, J. (2009). Media saturation, communication exposure and HIV stigma in Nigeria. Social Science and Medicine, 68, 1513e1520. https://doi.org/10.1016/j.socscimed.2009.01.026

Befort, C. A., Greiner, K. A., Hall, S., Pulvers, K. M., Nollen, N. L., Charbonneau, A., Kaur, H., \& Ahluwalia, J. S. (2006). Weight-related perceptions among patients and physicians: how well do physicians judge patients' motivation to lose weight? Journal of General Internal Medicine, 21, 1086-1090. https://10.1111/j.1525-1497.2006.00567.x

Bleich, S. N., Pickett-Blakely, O., \& Cooper, L. A (2011). Physician practice patterns of obesity diagnosis and $\begin{array}{llll}\text { weight-related counselling. Patient Education } & \text { Counselling, } & \text { 82(1), } & \text { 123-129. }\end{array}$ https://10.1016/j.pec.2010.02.018

Brown, I. (2006). Nurses' attitudes towards adult patients who are obese: literature review. Journal of Advanced Nursing, 53, 221-232. https://10.1111/j.1365-2648.2006.03718.x_

Brown, I., \& Thompson, J. (2007). Primary care nurses' attitudes, beliefs, and own body size in relation to obesity management. Journal of Advanced Nursing, 60, 535-543. https://doi.org/10.1111/j.1365-2648.2007.04450.x

Brown, I., Thompson, J., Tod, A., \& Jones, G. (2006). Primary care support for tackling obesity: A qualitative study of the perceptions of obese patients. British Journal of General Practice, 56, 666-672.

Camden, S. (2009). Obesity: An Emerging Concern for Patients and Nurses. OJIN: The Online Journal of Issues in Nursing, 14(1).

Corrigan, P. W., Morris, S. B., Michaels, P. J., Rafacz, J. D., \& Rüsch, N. (2012). Challenging the public stigma of mental illness: a meta-analysis of outcome studies. Psychiatric Services, 63, 963e973. https://doi.org/10.1176/appi.ps.201100529 
Dalal, A. K. (2006). Social interventions to moderate discriminatory attitudes: the case of the physically challenged in India. Psychology, Health and Medicine, 11, 374e382. https://doi.org/10.1080/13548500600595392

Diop, W. (2000). From government policy to community-based communication strategies in Africa: lessons from Senegal and Uganda. Journal of Health Communication, 5, $113 \mathrm{e} 117$. https://dx.doi.org/10.1080/10810730508956572

Durso, L. E., \& Latner, J. D. (2008). Understanding self-directed stigma: Development of the weight bias Internalization scale. Obesity, 16, s80-s86. https:// doi.org/10.1038/oby.2008.448

Epstein, L., \& Ogden, J. (2005). A qualitative study of GPs' views of treating obesity. British Journal of General Practice, 55, 750-754.

Flint, S.W. (2015). Obesity stigma: Prevalence and impact in healthcare. British Journal of Obesity, 1, 14-18.

Flint, S. W., Hudson, J., \& Lavallee, D. (2013). Counter-conditioning as an intervention to modify anti-fat attitudes. Health Psychology Research, 1, 122-5. https://doi.org/10.4081/hpr.2013.e24

Gapinski, K. D., Schwartz, M. B., \& Brownell, K. D. (2006). Can television change anti-fat attitudes and behaviour? Journal of Applied Biobehavioural Research, 11, 1-28. https://doi.org/10.1111/j.1751-9861.2006.tb00017.x

Goffman, E. (1963). Stigma: Notes on the Management of Spoiled Identity. Englewood Cliffs, New Jersey: Prentice-Hall.

Greenwald, A. G., McGhee, D. E., \& Schwartz, J. L. (1998). Measuring individual differences in implicit cognition: the implicit association test. Journal of Perspectives in Social Psychology, 74, 1464-80. http://dx.doi.org/10.1037/0022-3514.74.6.1464

Hankey, C., Eley, S., Leslie, W., Hunter, C., \& Lean, M. (2003). Eating habits, beliefs, attitudes and knowledge among health professionals regarding the links between obesity, nutrition and health. Public Health Nutrition, 7, 337-343.

Harvey, E. L., \& Hill, A. J. (2001). Health professionals' views of overweight people and smokers. International Journal of Obesity, 25, 1253-1261.

Harvey, E. L., Summerbell, C. D, Kirk, S. F. L., \& Hill, A. J. (2002). Dietitians' views of overweight and obese people and reported management practices. Journal of Human Nutrition and Dietetics, 15, 331-347. https://doi.org/10.1079/PHN2003526

Health and Social Care Information Centre. (2014). Statistics on Obesity, Physical Activity and Diet: England. Retrieved from http://bit.ly/Z02odv (20 March 2017).

Heijnders, M., \& Van Der Meij, S. (2006). The fight against stigma: an overview of stigma-reduction strategies and interventions. Psychology, Health and Medicine, 11, 353e363. https://doi.org/10.1080/13548500600595327

Hitchcock, N., \& Pugh, J. (2002). Management of overweight and obese adults. British Medical Journal, 325, 757-761. https://doi.org/10.1136/bmj.325.7367.757

Johnson, B. T., Redding, C. A., DiClemente, R. J., Mustanski, B. S., Dodge, B., Sheeran, P., et al. (2010). A network-individual-resource model for HIV prevention. AIDS and Behaviour, 14, 204e221. https://doi.org/10.1007/s10461-010-9803-z

Keyworth, C., Peters, S., Chisholm, A., \& Hart, J. (2013). Nursing students' perceptions of obesity and behaviour change: implications for undergraduate nurse education. Nurse Education Today, 33(5), 481-485. https://doi.org/10.1016/j.nedt.2012.05.016

Kushner, R. F., Zeiss, D. M., Feinglass, J. M., \& Yelen, M. (2014). An obesity educational intervention for medical students addressing weight-bias and communication skills using standardized patients. BioMed Central Medical Education, 14(53), 2-8. https://doi.org/10.1186/1472-6920-14-53

Latner, J. D., \& Stunkard, A. J. (2003). Getting worse: the stigmatization of obese children. Obesity, 11(3), 452-456. https://doi.org/10.1038/oby.2003.61

Latner, J. D., O'brien, K. S., Durso, L. E., Brinkman, L. A., \& MacDonald, T. (2008). Weighing obesity stigma: the relative strength of different forms of bias. International Journal of Obesity, 32(7), 1145-52. https://doi.org/10.1038/ijo.2008.53 
Martin, L. R., Williams, S. L., Haskard, K. B., \& DiMatteo, M. R. (2005). The challenge of patient adherence. Therapeutics and clinical risk management, 1(3), 189.

Loomis, G. A. (2001). Attitudes and practices of military family physicians regarding obesity. Military medicine, $166(2), 121$

Mercer, S. W., \& Tessier, S. (2001). A qualitative study of general practitioners' and practice nurses' attitudes to obesity management in primary care. Health bulletin, 59(4), 248-253.

Merrill, E., \& Grassley, J. (2008). Women's stories of their experiences as overweight patients. Journal of advanced nursing, 64(2), 139-146.

National Health Service England. (2014). Joined up Clinical Pathways for Obesity: Report of the Working Group. Retrieved 20 March, 2017, from http://bit.ly/RNNm7S

National Institute for Clinical Excellence. (2006). Orlistat for the treatment of obesity in adults. Guidance No. 22. Retrieved 20 March, 2017, from http://www.nice.org.uk

National Institute for Clinical Excellence. (2006). Obesity. Guidance on the Prevention, Identification, Assessment and Management of Overweight and Obesity in adults and children. Retrieved 20 March, 2017, from http://www.nice.org.uk/guidance/CG43/niceguidance/word/English

O'brien, K. S., Puhl, R. M., Latner, J. D., Mir, A. S., \& Hunter, J. A. (2010). Reducing anti - fat prejudice in preservice health students: a randomized trial. Obesity, 18(11), 2138-2144. https://doi.org/10.1038/oby.2010.79

Ogden, J., Bandara, I., Cohen, H., Farmer, D., Hardie, J., Minas, H., \& Whitehead, M. A. (2001). General practitioners' and patients' models of obesity: whose problem is it? Patient education and counseling, 44(3), 227-233. https://doi.org/10.1016/S0738-3991(00)00192-0

Persky, S., \& Eccleston, C. P. (2011). Impact of genetic causal information on medical students' clinical encounters with an obese virtual patient: health promotion and social stigma. Annals of Behavioral Medicine, 41(3), 363-372. https://doi.org/10.1007/s12160-010-9242-0

Poustchi, Y., Saks, N. S., Piasecki, A. K., Hahn, K. A., \& Ferrante, J. M. (2013). Brief intervention effective in reducing weight bias in medical students. Family medicine, 45(5), 345.

Puhl, R. M., \& Heuer, C. A. (2009). Weight bias: a review and update. Obesity (Silver Spring), 17(5), $941-964$. https://doi.org/10.1038/oby.2008.636

Puhl, R. M., Schwartz, M. B., \& Brownell, K. D. (2005). Impact of perceived consensus on stereotypes about obese people: a new approach for reducing bias. Health Psychology, 24(5), 517. https://doi.org/10.1037/0278-6133.24.5.517

Reeves, G. K., Kirstin, P., Valerie, B., Jane, G., Elizabeth, S., \& Diana, B. (2007). Cancer incidence and mortality in relation to body mass index in the Million Women Study: cohort study. British Medical Journal, 335, 1134-1145. https://doi.org/10.1136/bmj.39367.495995.AE

Rudman, L. A. (2004). Sources of implicit attitudes. Current Directions in Psychological Science, 13, 79-82

Stangor, C., Sechrist, G. B., Jost, J. T. (2001). Changing beliefs by providing consensus information. Perspectives of Social Psychology Bulletin, 27, 486-496. https://doi.org/10.1177/0146167201274009

Swift, J. A., Hanlon, S., El-Redy, L., Puhl, R. M., \& Glazebrook, C. (2013a). Weight bias among UK trainee dietitians, doctors, nurses and nutritionists. Journal of Human Nutrition Diet, 26, $395-402$. https://doi.org/10.1111/jhn.12019

Swift, J. A., Tischler, V., Markham, S., Gunning, I., Glazebrook, C., Beer, C., \& Puhl, R. (2013b). Are anti-stigma films a useful strategy for reducing weight bias among trainee healthcare professionals? Results of a pilot randomized control trial. Obesity Facts, 6, 91-102. https://doi.org/10.1159/000348714

Tailor, A., \& Ogden, J. (2009). Avoiding the term "obesity": an experimental study of the impact of doctors' language on patients' beliefs. Patient Education and Counselling, 76, $260-4$. https://doi.org/10.1016/j.pec.2008.12.016

Teachman, B. A., Gapinski, K. D., Brownell, K. D., Rawlins, M., \& Jeyaram, S. (2003). Demonstrations of implicit anti-fat bias: the impact of providing causal information and evoking empathy. Health Psychology, $22,68-78$. 
The guardian. (2014). Obesity- obesity can be a disability, EU court rules. Retrieved 22 March, 2017, from http://www.theguardian.com/society/2014/dec/18/obesity-can-be-disability-eu-court-rules

Thompson, R. L., \& Thomas, D. E. (2000). A cross-sectional survey of the opinions on weight loss treatments of adult obese patients attending a dietetic clinic. International Journal of Obesity, 24, 164-170.

Walton, G. M., \& Cohen, G. L. (2011). A brief social-belonging intervention improves academic and health outcomes of minority students. Science, 331, 1447e1451. https://doi.org/10.1126/science.1198364

Wardle, J., Waller, J., \& Fox, E. (2002). Age of onset and body dissatisfaction in obesity. Addictive Behaviours, 27, 561-573. https://doi.org/10.1016/S0306-4603(01)00193-9

Wear, D., Aultman, J. M., Varley, J. D., \& Zarconi, J. (2006). Making fun of patients: medical students' perceptions and use of derogatory and cynical humour in clinical settings. Academic Medicine, 81, 454-62. https://doi.org/10.1097/01.ACM.0000222277.21200.a1

Wee, C. C., McCarthy, E. P., Davis, R. B., \& Phillips, R. S. (2000). Screening for cervical and breast cancer: is obesity an unrecognized barrier to preventive care? Annals of Internal Medicine, 132, 699-704

Wee, C.C., Philips, R.S., Cook, E.F., Haas, J.S., Puopolo, A.L., Brennan, T.A. and Burstin, H.R. (2002). Influence of body weight on patients' satisfaction with ambulatory care. Journal of General Internal Medicine, 17, 155-159. https://doi.org/10.1046/j.1525-1497.2002.00825.x

Wigton, R. S., \& McGaghie, W. C. (2001). The effect of obesity on medical students' approach to patients with abdominal pain. Journal of General Internal Medicine, 16, 262-5. https://doi.org/10.1046/j.1525-1497.2001.016004262.x

Yeager, D. S., \& Walton, G. M. (2011). Social-psychological interventions in education: they're not magic. Review of Educational Research, 81, 267e301. https://doi.org/10.3102/0034654311405999

Zuzelo, P. R., \& Seminara, P. (2006). Influence of registered nurses' attitudes toward bariatric patients on educational programming effectiveness. Journal of Continuing Education in Nursing, 37, 65-73.

\section{Copyrights}

Copyright for this article is retained by the author(s), with first publication rights granted to the journal.

This is an open-access article distributed under the terms and conditions of the Creative Commons Attribution license (http://creativecommons.org/licenses/by/4.0/). 